International Business Management 6(4): 400-407, 2012

ISSN: $1993-5250$

(C) Medwell Journals, 2012

\title{
Analysis of Direct Measurement PEO Attainment Via Qualitative Method to Fulfill Washington Accord Accreditation Criteria: A Case Study
}

\author{
1, 2, ${ }^{3}$ Mohammad Syuhaimi Ab-Rahman, ${ }^{2}$ Hadi Guna, ${ }^{2}$ Mohammad Najib Mohammad Saupe, \\ ${ }^{3}$ Nasharuddin Zainal and ${ }^{3}$ Hafizah Husin \\ ${ }^{1}$ Spectrum Technology Research Group (SPECTECH), \\ ${ }^{2}$ Research Advancement Strategy and Planning (RASP), \\ ${ }^{3}$ Department of Electrical, Electronics and Systems Engineering, \\ Faculty of Engineering and Built Environment, Universiti Kebangsaan Malaysia, \\ 43600 Bangi, Selangor Darul Ehsan, Malaysia
}

\begin{abstract}
Program Educational Objective ( $\mathrm{PEO}$ ) is a long-term performance which measured after the graduates work for $>3$ years. It is important to measure the achievement of a university in producing high quality graduates who are equipped with a variety of technical and generic skills. One method to measure the PEO is to conduct the questionnaire with respect to the background of a former university graduates who are called alumni. A website has been constructed to facilitate the respondents to answer some questions in the questionnaire and further analysis results are automatically generated. The results obtained are displayed in an different annual range and overall performance which varying according to the parameters that have been determined. The data obtained were analyzed using two approaches such as average and percentage achievement.
\end{abstract}

Key words: Alumni, Program Educational Objective (PEO), survey, achievements, graduates, Malaysia

\section{INTRODUCTION}

Education has now changed direction from the education that is based on the inputs (time and content) to the education based on the objectives. It focuses more on the ability of the students themselves to do something after them through the learning process. In other words, it is more focused on learning outcomes which it will be a destination and direction of students. Therefore, the best way to achieve this goal is to identify the direction which then backwards planning and selecting the best path to reach the desired destination.

In an effort to produce graduates with a balanced and an excellent university, the curriculum should be made through the university censorship Philosophy of Education, the Education Act (1996), the international requirements and educational psychology. Thus, according to Hamid (2004), university curricula must have a vision and mission, goals and objectives, learning outcomes, curriculum content, organization of curriculum content, teaching and learning strategies and assessment. (Hamid, 2004).

Among the most important in formulating the new curriculum is a redefined the objectives of the learning program (Programme Educational Oobjectives (PEO)), which reflects the characteristics of graduates who wish to produce and it must be achieved within a few years after completing graduate studies at the university. This objective is also to improve quality assurance in terms of teaching and learning process (Hamid, 2004).

In addition, the Programme Outcomes (PO) should be formulated and measured using a specific method of the program and after graduation students (Abdullah et al., 2007). The results of this program are to identify and assess the desired outcomes and help to produce graduates who are well balanced and excellent (Ben-David, 1999). Thus, both program objectives and program outcomes should be provided in drafting the new curriculum.

Therefore to develop a neat and intact $\mathrm{PEO}$ and relevant to the needs of the profession, the opinion of graduates and alumni must be taken into account through a questionnaire which can access on-line. Hence, this study presents the results of surveys based on the characteristics of each statement PEO. Questionnaires are also defined to be the direct measurement method for all alumni are asked to enter their information into the template provided. Then, the measurement of performance evaluation is done automatically.

Corresponding Author: Mohammad Syuhaimi Ab-Rahman, Spectrum Technology Research Group (SPECTECH), Faculty of Engineering and Built Environment, Universiti Kebangsaan Malaysia, 43600 Bangi, Selangor Darul Ehsan, Malaysia 


\section{PROGRAM EDUCATIONAL OBJECTIVES (PEO)}

PEO 1 = An engineer with an understanding of the fundamental knowledge prerequisite for the role as an efficient engineer

$\mathrm{PEO} 2$ = An engineer with professional attitudes and ethics necessary in fulfilling his/her responsibilities towards the creator, client and the society

PEO 3 = An engineer who will uphold the Malay language as a language of knowledge in the engineering field and at the same time has the ability to communicate in English

$\mathrm{PEO} 4$ = An engineer who is able to adapt him/herself to the international/global work environment

PEO 5 = An engineer who is able to lead an engineering organisation based on knowledge of important current issues in engineering

PEO 6 = An engineer who is able to conduct research in the field of engineering whether at a postgraduate level or in his/her own organisation

The formulated PEOs are consistent with the vision and mission of the university and faculty and have been formulated to directly ensure the achievement of the mission and vision of university and the faculty.

These PEOs are also consistent with stakeholders' (such as employers, parents, alumni and students) requirements. In fact, these are the main criteria considered towards the formulation of the PEOs as required by the Engineering Accreditation Council (2007) manual. Achievements of these PEOs reflect achievement of vision and mission of the university and faculty as well as satisfying the stakeholders' requirements since the PEOs, vision and mission and stakeholders' requirements are interlinked. PEO 1, 2, 4 and 5 are common to many engineering programs in Malaysia (Engineering Accreditation Council, 2007) and elsewhere in the world to produce competent engineers with a strong understanding of fundamental engineering knowledge
(PEO1), engineers with professional attitudes and ethics necessary in fulfilling his/her responsibilities towards the creator, client and the society ( $\mathrm{PEO} 2$ ), engineers who are able to adapt to the international/global researche environment ( $\mathrm{PEO} 4)$ and engineers who are leaders in their respective organisations (PEO5). These are also in line with the vision of university which is committed to be the leading university that pioneers innovations in creating a dynamic, knowledgeable and ethical society. During the process to establish these PEOs, feedback and input are obtained from the stakeholders via direct consultation and questionnaires. The feedback and responses revealed that the PEOs are aligned with the stakeholders' needs. In accomplishing the university and faculty mission and vision, EESE Department emphasizes the following core values: leadership and innovation, creativity, novel application of fundamental engineering science, interdisciplinary activities, community of ethical scholars, development of future leaders and professionalism (Engineering Accreditation Council, 2007; $M Q F$, 2009). Thus, the PEOs are consistent with the institutional and faculty goals. Specifically, the common themes of creative discovery, leadership and individual responsibility emerge in all of these mission statements and educational objectives. As such, the department has set a 5 year period for all students to accomplish these PEOs. Table 1 shows the PEOs, targeted achievements of the objectives after 5 years of graduation that are used to measure the achievements of the outcomes.

Besides being consistent with the mission, vision and stakeholders needs, the formulated PEOs are also related to the established Program Outcomes (Pos). PEOs are the most important driving factors towards the development of the curriculum in terms of approach, content, delivery, assessment, analyses and evaluation. In formulating the $\mathrm{PEOs}$, attention and care are given towards ensuring that the PEOs fulfill the following indicators:

- $\quad$ Specific, defined, measurable and achievable

- Have own niche

Table 1: Targeted Achievements (TA) for each PEO

\begin{tabular}{ll} 
Program educational objective & Targeted achievement \\
$\begin{array}{l}\text { PEO 1: An engineer with an understanding of the fundamental } \\
\text { knowledge prerequisite for the role as an efficient engineer }\end{array}$ & TA: $70 \%$ of graduates work as engineers \\
$\begin{array}{l}\text { PEO 2: An engineer with professional attitudes and } \\
\text { ethics necessary in fulfilling his/her responsibilities towards } \\
\text { the creator, client and the society }\end{array}$ & TA: $10 \%$ of graduates involved in professional bodies and social activities \\
$\begin{array}{l}\text { PEO 3: An engineer who will uphold the Malay language as } \\
\text { a language of knowledge in the engineering field and at the } \\
\text { same time has the ability to communicate in English }\end{array}$ & $\begin{array}{l}\text { TA: } 60 \% \text { of respondents agree that the Malay language is very important } \\
\text { in communications }\end{array}$ \\
$\begin{array}{l}\text { PEO 4: An engineer who is able to adapt him/herself to the } \\
\text { international/global work environment }\end{array}$ & TA: $10 \%$ of graduates work in international companies and/or related bodies \\
$\begin{array}{l}\text { PEO 5: An engineer who is able to lead an engineering organization } \\
\text { based on knowledge of important current issues in engineering }\end{array}$ & TA: $5 \%$ of graduates become managers of engineering organizations \\
$\begin{array}{l}\text { PEO 6: An engineer who is able to conduct research in the field } \\
\text { of engineering whether at a postgraduate level or in his/her own organization }\end{array}$ & TA: $10 \%$ of graduates proceed to research based postgraduate studies or work \\
\hline
\end{tabular}


Int. Business Manage., 6 (4): 400-407, 2012

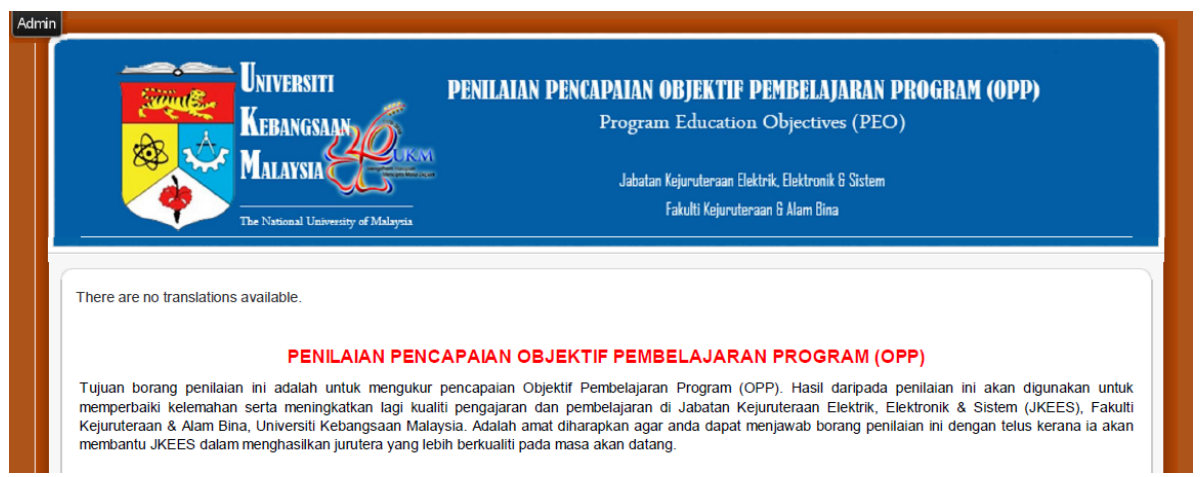

Fig. 1: Header for on-line survey form

- Consistent and linked to mission and vision of university, faculty and stakeholders needs

- Established process for formulating

- Involvement of stakeholders in defining the objectives

- Continually reviewed and updated, i.e., Continual Quality Improvement (CQI)

In establishing the PEOs, the needs and requirements from various stakeholders are of utmost importance and therefore their views are taken into considerations. These stakeholders include faculty members, students, alumni, members from the industries and also parents. The views are collected by means of surveys and formal meetings. Having these elements in the process of formulating its $\mathrm{PEOs}$, the faculty has fulfilled the intended requirements.

\section{PEO QUESTIONAIRE}

For alumni questionnaires, a set of forms containing all PEO statements with features that make all the statements that have been prepared and developed in line (http://pkukmweb.ukm.my/OPP/).

Assessment of each statement is made using 1-3 Likert scale. Next, these forms are analyzed automatically through the Faculty of Engineering and Built Environment Alumni database. The header for the website online form is shown in Fig. 1.

To enable a more in-depth analysis of the input provided by the alumni, each alumnus is asked to enter the information on themselves. They are also required to inserting the information on their studies as shown in Fig. 2. The subsequent sections present the data analysis and interpretation of the alumni surveys. Effort is being pursued by the department $\mathrm{OBE}$ committee to revise the form and the final draft of the proposed changes of the form will be tabled at the next department meeting for endorsement before being table at the faculty QA meeting.

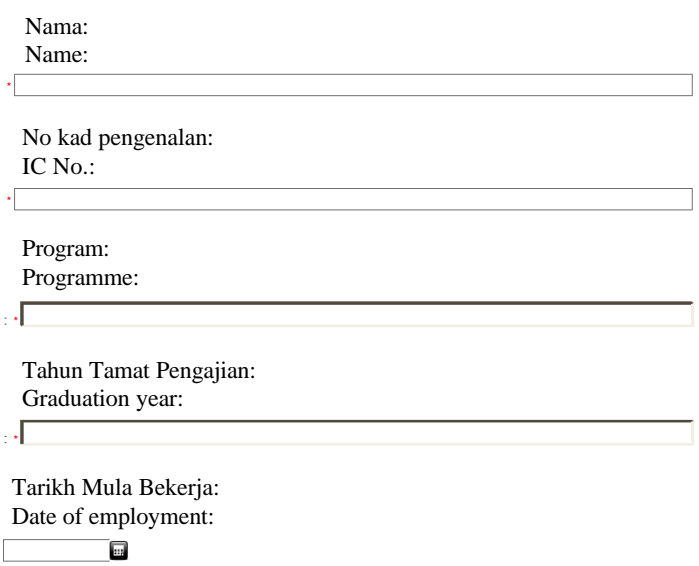

Fig. 2: Profile form to be filled by alumni

\section{DISCUSSION}

Analysis of the alumni survey was conducted in two forms:

- Average achievement

- Percent achievement

Alumni achievement refers to the average calculation based on the average performance for all alumni Likert scale. It is important to provide information on alumni as a whole in the achievement of each PEO. For example, a $\mathrm{PEO} 1$ for the 2000-2005 batch has value 3 which shows all the alumni of the year was achieved with excellence of PEO1. The second analysis is the percentage of alumni based on the number of alumni achievement of the objectives of the number of alumni who provide feedback (respondents).

Each PEO has the following target and performance can be measured by the achievement of these goals. A total of 56 alumni from the years 2000-2010 has responded in the questionnaire. 
Average achievement: Reviews of the latest analysis of questionnaires for the attainment $\mathrm{PEO}$ obtained from graduates of the Department of Electrical, Electronics and Systems Engineering began in January, 2010. The results of the survey of self-evaluation from 2000-2009 are shown in Fig. 3. Score obtained was the scale of $1-3$ where 1 indicates the weakest competence or in other words, the objective is not achieved while 3 represents the most powerful competence where the respondents have achieved the objectives for each $\mathrm{PEO}$. For every $\mathrm{PEO}$ that represents a very significant soft-skill; PEO 1 is basic engineering knowledge, $\mathrm{PEO} 2$ is professional behavior and ethics, PEO 3 is communication ability either in Malay or English, $\mathrm{PEO} 4$ is the ability to adapt to the international/global working environment, $\mathrm{PEO} 5$ is leadership skill and PEO 6 is the involvement in R\&D. Figure 3 shows that on average, the highest $\mathrm{PEO}$ for obtaining degree as the respondents' basic ability for all 3 years, almost all respondents have a basic knowledge on a scale of 2-3 in which case the objective of PEO 1 is achieved. Meanwhile for PEO 5, the leadership skill for each batch is still very weak and this matter should be noted to encourage the faculty/university to give more priority on leadership skill of prospective graduates in the future.

If researchers compare these three batches, the respondents who obtained their degrees in 2000-2005 had the highest score in achieving the six objectives followed by 2006-2008 and 2009 batches. It seems obvious that leadership ability and involvement in R\&D by batch 2009 increased when compared with the previous 3 years. A highly significant decrease in all five PEOs (PEO 1, PEO 2, $\mathrm{PEO} 4$, PEO 5 and PEO 6) for each year was seen, except for communication skill ( $\mathrm{PEO} 3$ ) which does not exceed the score of 0.25 . Although, this batch (2000-2005 and 2006-2008) are not OBE batches but the curriculum that has been developed is directed to the $\mathrm{PEO}$ attainment and each $\mathrm{PEO}$ has been achieved with excellence and

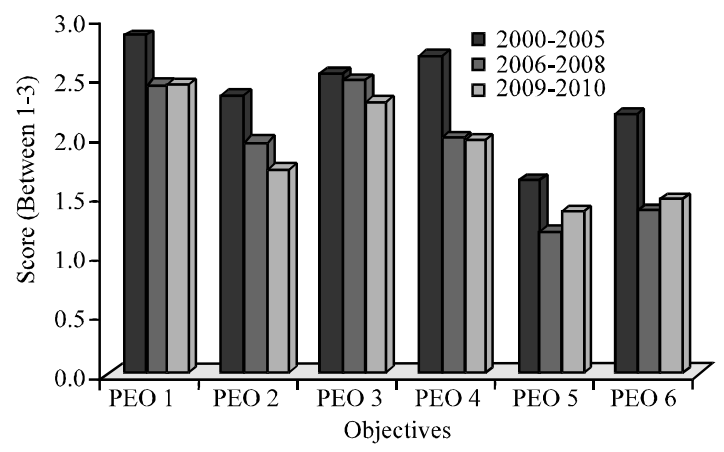

Fig. 3: The average performance of each division $\mathrm{PEO}$ by degree obtained take a long time at least 4 years to see a more significant achievement. There was an increase on the achievement of PEO in 2006-2008 batches and initial performance of 2009-2010 batches is something to be proud of. In conclusion, the alumni survey statistics from 2000-2010 showed an increase in the performance of each $\mathrm{PEO}$ each year and there are system improvements to ensure that each $\mathrm{PEO}$ is achieved.

Achievements of the initial PEO obtained by alumni who graduated in 2000-2005 can be explained by Fig. 4a. The results of the observation results of questionnaires showed that the overall performance of the alumni are
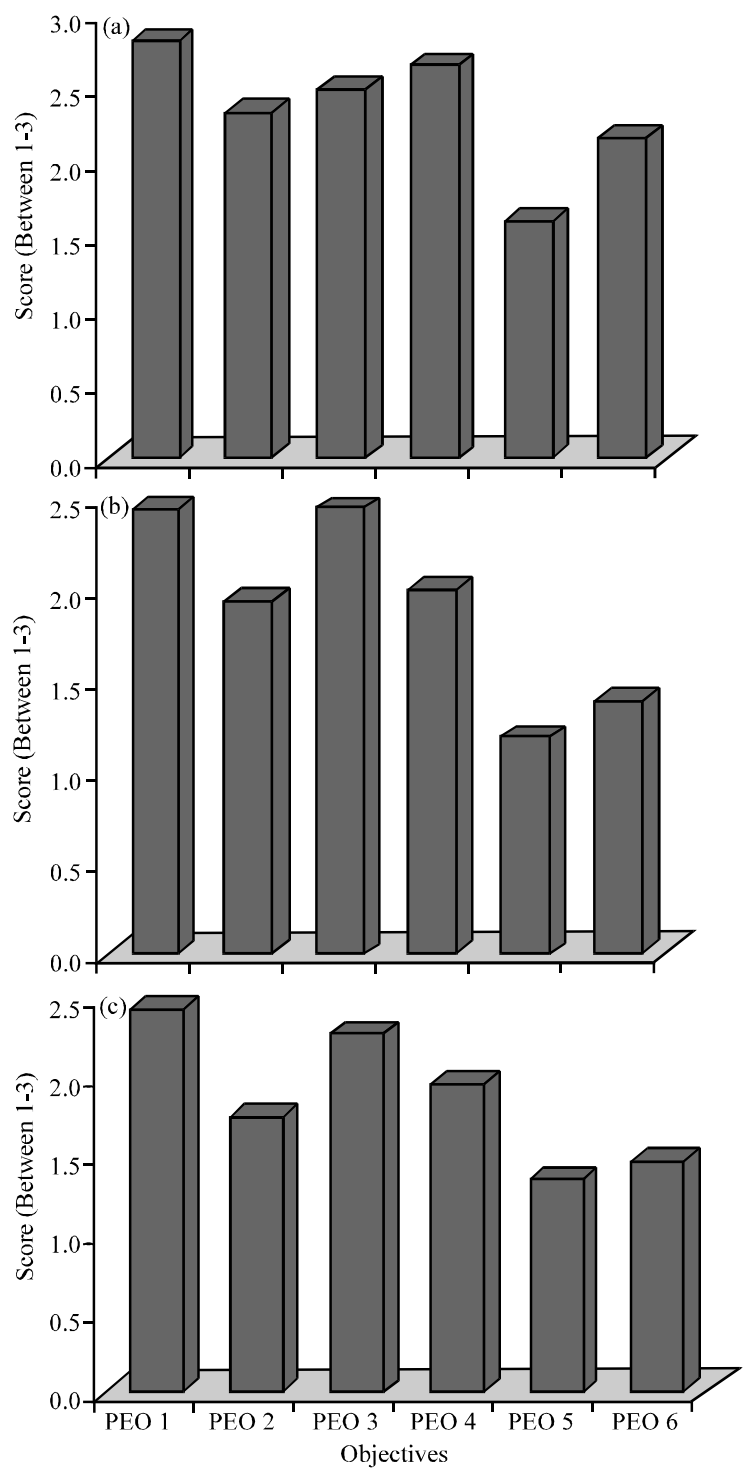

Fig. 4: Average performances for $\mathrm{PEO}$ by year of graduation: a) 2000-2005; b) 2006-2008; c) 20092010 
good which is the rating for each $\mathrm{PEO}$ mostly located on the score of 2-3. It shows that the $\mathrm{PEO}$ for this batch are generally said to be achieved. Basic ability (PEO 1) is the highest achievement, followed by the ability to adapt to working conditions ( $\mathrm{PEO} 4$ ) while the lowest is the leadership ability (PEO 5) and is followed by an interest in venturing into the field of research (PEO6).

While Fig. $4 \mathrm{~b}$ also displays the achievements of alumni who PEO graduated in 2006-2008. The results of the observation results of questionnaires showed that the overall performance of the alumni are good which is the rating for each $\mathrm{PEO}$ mostly located on the score of 2-3, especially for $\mathrm{PEO} 1-\mathrm{PEO}$ 4. Basic knowledge of and ability to communicate $\mathrm{PEO} 1$ are two of the highest achievements of this batch. As occurred in the 2000-2005 batches, the lowest PEO is leadership ability, followed by an interest in venturing into research.

Achievement of $\mathrm{PEO}$ obtained by alumni who graduated in 2009 is shown in Fig. 4c. The results of the distributed questionnaires showed that the overall performance of the alumni is good where the rating for each PEO mostly scores 2-3, especially for PEO 1-PEO 4. Just as in the 2006-2008 batches, basic skills scores the highest, followed by the ability to adapt to working conditions while the lowest is leadership ability and followed by an interest in venturing into the field of research. From observation, the pattern graphs for all three batches for all PEO are almost the same (Fig. 5) but the rate of decline in scores is decreasing every year which means the university has to take more a significant action to raise the scores of alumni by following the $\mathrm{PEO}$ that has been set.

On average, over the past 10 years, all six $\mathrm{PEO}$ achievements are at a good level. This is shown in Fig. 6, of which three of the PEO have achieved category

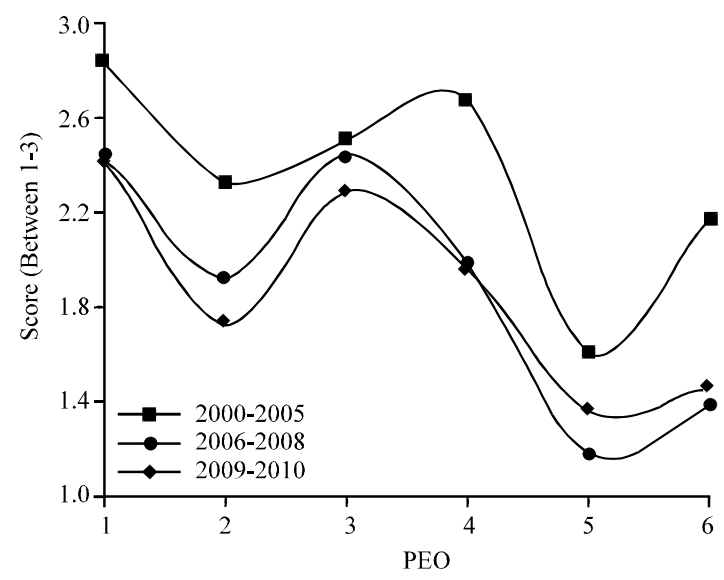

Fig. 5: Graphic patterns for the three batch alumni for each $\mathrm{PEO}$ objectives which are basic knowledge, communication skills and ability to adapt to the global working environment. Meanwhile for PEO 2 and 6, the ability of professional ethics and attitudes and engagement with R\&D is still in a fairly safe score while PEO 5 or graduate leadership skill is at the most critical level but still in the but still in the minimal objective achieving category.

In this study, a total of six PEO have been analyzed on 56 respondents who are alumni and graduates from the programs of the Department of Electrical, Electronics and Systems Engineering. Overall, PEO is considered as able to support the vision, mission and philosophy of the university. PEO achievement is measured using an indirect assessment through surveys of alumni and graduates. This study is able to establish a measurement process that can measure the achievement of desired outcomes and to highlight best practices that should be followed and to identify the part that needs to be improved wholly.

Percentage of achievement: Refer to objective achievement graph, there were two major data observed. First is level of achievement from respondents and the second data is about the percentage of targeted achievement. This target can refer to a performance indicators shown in Table 1. Each PEO have a different percentage. For example, $\mathrm{PEO} 1$ have a targeted achievement about $70 \%$ of graduates research as engineers while $\mathrm{PEO} 2$ have a targeted achievement about $10 \%$ graduated involved in professional bodies and social activities. Dashed red line in Fig. 7 shows a targeted achievement while blue histogram indicates a percentage of collected data from respondent. Both data will be compared whether the respondents achieve above or below then the threshold (targeted achievement).

From the Fig. 7a, objective achieved is about 30\% above the targeted achievements of the objectives after

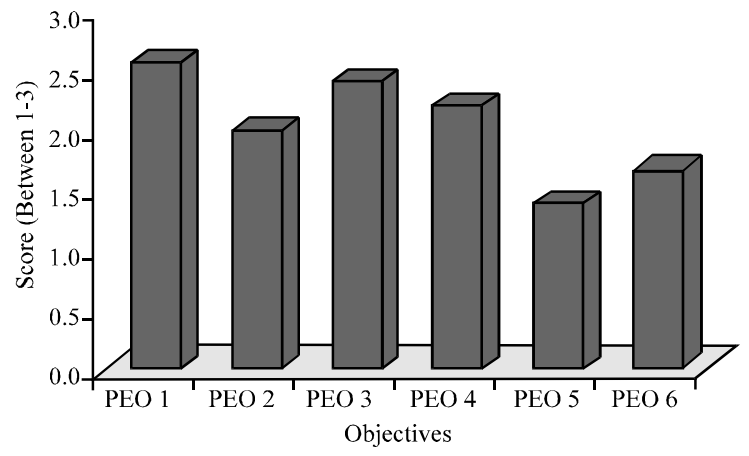

Fig. 6: Overall performances for each $\mathrm{PEO}$ by year of graduation 2000-2010 
Int. Business Manage., 6 (4): 400-407, 2012
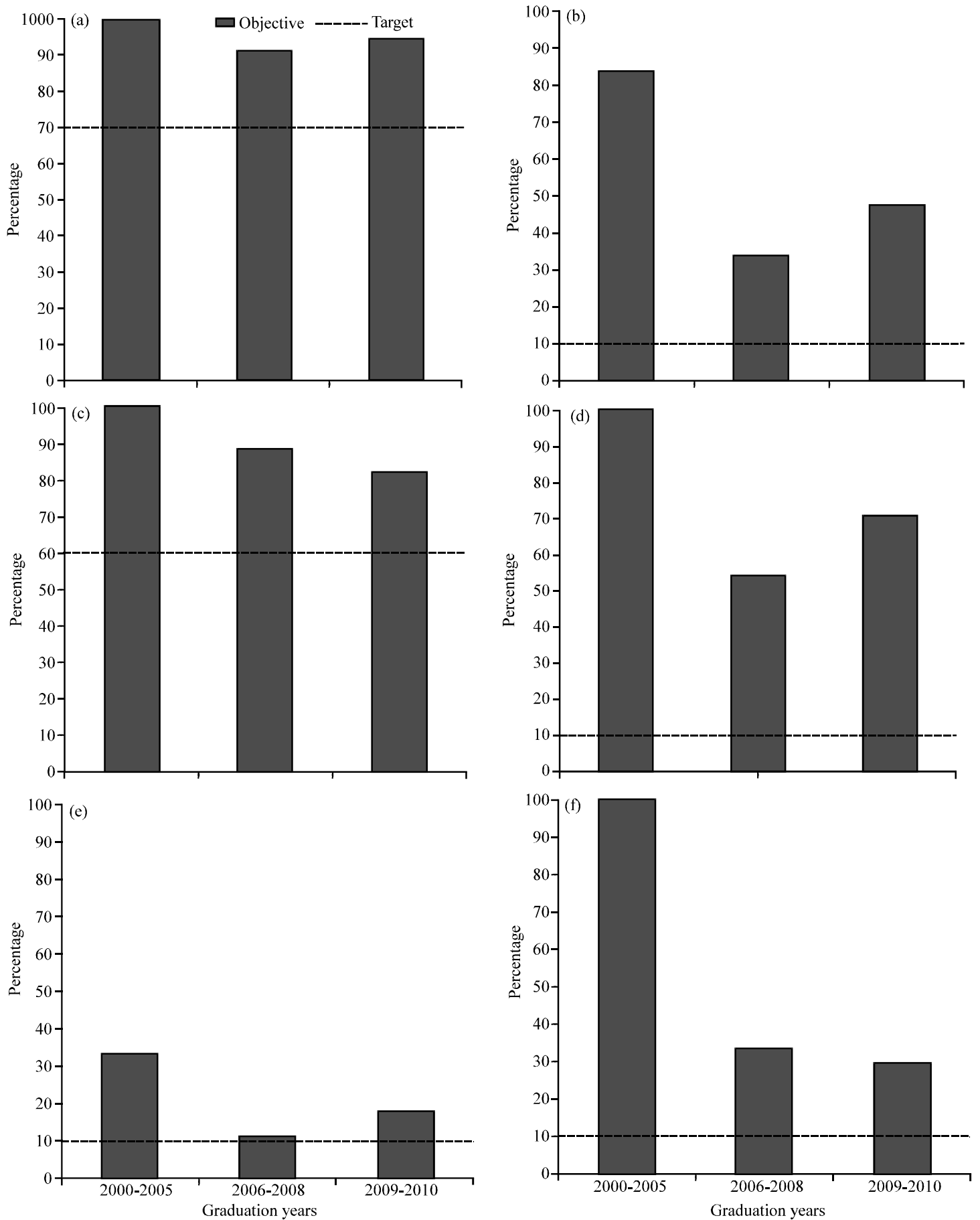

Fig. 7: Targeted and achieved objectives: a) PEO 1; b) PEO 2; c) PEO 3; d) PEO 4; e) PEO 5; f) PEO 6

10 years of graduation. About $>90 \%$ each batch of graduates works as an engineer while at the same time department has set at least $70 \%$ of them research in these field. For respondent graduated in 2000-2005 get the highest percentage while batch 2006-2008 get the lowest score but in 2009 the percentage has been improved. About $<10 \%$ of respondent in 2006 until 2009 are not involved in engineer field, most of them are join government or company based on social science's knowledge such as administrative and diplomatic officer, teachers, business and bank. Almost all of respondent get a job based on their quality and their qualifications which 
relevant with their program/courses took in university. $\mathrm{PEO} 2$ states that engineers must acquire professional attitudes and ethics necessary in fulfilling his/her responsibilities towards the creator, client and the society Fig. 7b. The performance of respondent also above the targeted achievement. The best performance shown in batch 2000-2005 reach 84\% achieved the objectives. Critical point found in 2004-2008 batch which $34 \%$ alumni only able to perform their professional ethics but in 2009 alumni tried to improve their achievement is about $10 \%$ increased. In the future, university has a responsibility to train them well to make sure they can upgrade another $50 \%$ of alumni to enhance their professional attitude and ethics on their career. From the data said that at least 5 respondents in 2000-2005 batch, 27 respondents in 2006-2008 and 11 respondents in 2009 from total of 56 respondents shows that they are able to control their emotion and their anger in their career. About 15 respondents are members of professional bodies that related to engineering such as Board of Engineers Malaysia (BEM), IEM, IET, CDB, IEEE and IACSIT. And 15 respondents also officially registered as a BEM member. Here, 2000-2005 have the higher score on environmental awareness which almost $100 \%$ of respondent, followed by 2009 and 2006-2008 batch. Over 10 years, $<26 \%$ alumni are involved in any welfare or NGO program but the good news is $>97 \%$ of respondents are punctual in attending any appointment regarding their research.

As show in Fig. 7c, targeted achievements of the objectives of PEO 3 (communication skills) were obtained. It indicates that any deviation occurred about $10 \%$ in every batch. The deviation is not significant but the department has a bigger responsibility to enhance this $\mathrm{PEO}$ in order to avoid the deviation that happens for the next 5 or 10 years from now. Almost $100 \%$ respondent from 2000-2005 batch, 63\% from 2006-2008 and 58\% from 2009 alumni are able to use the proper Bahasa Melayu (Malay language) in their research, especially on their activity related to correspondence, report writing, preparation on minutes of meetings, calling, public speaking and services, etc. and all of the respondents said that they are able to speak well in English.

$\mathrm{PEO} 4$, response from alumni said that engineer who is able to adapt him/herself to the international/global research environment was shown in Fig. $7 \mathrm{~d}$. The $2000-2005$ batches still lead the score which is $100 \%$ of them able to adapt in international/global companies and/or related bodies, followed by $72 \%$ from $2009-2010$ batch and 54\% from 2006-2008 alumni. No more hesitation from respondent to interact with international company from major oil company, international bank, Internet service provider, university and others. It seems like department have to prioritize to enhance $\mathrm{PEO} 5$ regarding the ability of engineer to lead an engineering organization based on knowledge of important current issues in engineering. Knowing the fact that $\mathrm{PEO} 5$ has the lowest score compared to other PEOs (Fig. 7e). The highest score reach $<35 \%$ covered by respondent which graduated in 2000-2005. While, respondent of 2006-2008 stand in the lowest score are $<10 \%$ followed by $18 \%$ of $2009-2010$ batch. Some respondent thought that some skills that engineer have to mastered in order to win the employer's heart, some personal skills are surely noticed from the survey such as dedication in completing the research, responsible on work done, accuracy, fast learning, communication skill, leadership, research under pressure, negotiation skill, teamwork, etc. From overall results from respondent shows that $<30 \%$ alumni have $<10$ staffs research under their supervision, 10\% have between 11 and 20 subordinates, $5 \%$ have $>20$ subordinates and the rest did not response on the survey's question.

In PEO 6, refer to Fig. $7 f$ respondents graduated in 2000-2005 still leading the score while 34\% respondent from 2006-2008 and 30\% from 2009-2010 are need some motivation in order to attract them to conduct research in the field of engineering whether at a postgraduate level or in his/her own organization. From overall results shows that $<45 \%$ of alumni are interact with Research and Development (R\&D) activity in engineering field such as program development, design works, nanotechnology, GIS analyzing, fiber optic, microprocessor and microcontroller, etc.

\section{USE OF RESULTS TO IMPROVE EFFECTIVENESS OF THE PROGRAMS}

The result from the surveys of 2000-2005, 2006-2008, 2009 represent the second cycle of PEOs evaluation. However, these results do not truly reflect the achievement of the graduates from the OBE program. The OBE students will only graduate in 2009 and their actual achievement if assessed in 3 years time can only be presented in 2012. In the meantime, the department will make use of the results to develop and improve the assessment tools to measure the PEOs achievement.

The results of the survey conducted, measuring the average of achievement for each batch showed PEO 2, 5 and 6 still not fully achieved. Therefore, the Department of Electrical, Electronics and Systems Engineering has taken several initiatives to improve performance through various efforts including: 
- Conducting seminars on the importance of BEM and the Professional Bodies Registration

- Organizing leadership courses

- Provide interesting initiatives to attract alumni to continue their studies to a higher level

However, according to the percentage of achievement analysis, all the $\mathrm{PEO}$ has reached its target.

\section{CONCLUSION}

In this study as many as six PEOs have been analyzed over 56 respondents who are alumni of programs in Department of Electrical, Electronics and Systems Eengineering. Overall, PEO was able to endorse the vision, mission and philosophy of the university. Attainment $\mathrm{PEO}$ was measured using a direct assessment through the review among alumni. This study could form the measurement process that can measure the achievement of desired learning outcomes and bring forward the best practice that should be followed as well as recognize certain portion which is necessary to improve upon it as a whole.

\section{REFERENCES}

Abdullah, S., N. Muhamad, R.A. Abdullah, O.K. Rahmat and B.M. Deros et al., 2007. Penilaian objektif dan hasil program pendidikan berasaskan hasil (OBE): Soal Selidik Majikan Indistri Dan Alumni. Seminar Pendidikan Kejuruteraan dan Alam Bina, Malaysia. http:/www.ukm.my/p3k/images/sppb07/21.pdf.

Ben-David, M.F., 1999. AMEE guide No. 14: Outcomebased education: Part 3-assessment in outcomebased education. J. Med. Teacher, 21: 23-25.

Engineering Accreditation Council, 2007. Engineering programme accreditation manual. Engineering Accreditation Council, Board of Engineers, Malaysia. http:/www.bem.org.my/v3/downloads.html.

Hamid, K.A., 2004. Garis panduan membina hasil pembelajaran (Learning outcomes) bagi kursus pengajian IPTS. Lembaga Akreditasi Negara. http://jpt.mohe.gov.my/RUJUKAN/GARIS\%20PA NDUAN/LearningOutcomesBM.pdf.

$\mathrm{MQF}$, 2009. Manual for preparing a self assessment report. Malaysian Qualification Framework. http://www.mqa.gov.my/en/utama_mqf.cfm. 